\title{
Professional practice in caring for maternal grief in the face of stillbirth in two countries
}

\author{
Prática profissional no cuidado ao luto materno diante do óbito fetal em dois países \\ Práctica profesional en el cuidado del duelo materno ante la muerte fetal en dos países
}

'Universidade Estadual do Oeste do Paraná. Francisco Beltrão, Paraná, Brazil.

"Université du Québec en Outaouais. Gatineau, Québec, Canadá.

"' Universidade Estadual de Maringá. Maringá, Paraná, Brazil.

How to cite this article:

Paris GF, Montigny F, Pelloso SM. Professional practice in caring for maternal grief in the face of stillbirth in two countries. Rev Bras Enferm. 2021;74(3):e20200253.

https://doi.org/10.1590/0034-7167-2020-0253

\section{Corresponding author:} Gisele Ferreira Paris E-mail: gfparis18@gmail.com

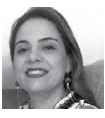

EDITOR IN CHIEF: Dulce Barbosa ASSOCIATE EDITOR: Ana Fátima Fernandes

\begin{abstract}
Objective: to understand professional care for maternal grief in the puerperium of stillbirth. Methods: a clinical-qualitative study with all the women who had stillbirths living in Maringá (Brazil) and participating in the Center d'Études et de Recherche in Family Intervention at the University of Quebec in Outaouais in Gatineau (Canada). Semi-structured interviews were carried out and the relevant aspects were categorized into themes. Results: the identified categories were: Assistance received in the puerperium with a focus on grief: hospital and outpatient environment, and Professional support in coping with maternal grief after fetal loss: with contact and memories, without contact and without memories and impossibilities of contact with the baby. Final considerations: the need for a multidisciplinary support and monitoring network for women who experienced fetal loss was evident. From this study, a routine of care for grief can be implemented in Brazil based on experiences in Canada. Descriptors: Fetal Death; Professional Practice; Bereavement; Brazil; Canada.
\end{abstract}

\section{RESUMO}

Objetivo: compreender o cuidado profissional ao luto materno no puerpério de nascimentos sem vida. Métodos: estudo clínico-qualitativo com todas as mulheres que tiveram óbito fetal, residentes em Maringá (Brasil) e participantes do Centre d'Études et de Recherche en Intervention Familiale na Universidade do Quebec em Outaouais no Gatineau (Canadá). Foi realizada entrevista semiestruturada, e os aspectos relevantes foram categorizados em temas. Resultados: as categorias identificadas foram Assistência recebida no puerpério com enfoque no luto: ambiente hospitalar e ambulatorial e Apoio profissional no enfrentamento ao luto materno após a perda fetal: com contato e lembranças, sem contato e sem lembranças e impossibilidades de contato com o bebê. Considerações finais: ficou evidente a necessidade de uma rede de apoio e o acompanhamento multiprofissional para mulheres que vivenciaram perda fetal. A partir deste estudo, uma rotina de atendimento de cuidados ao luto poderá ser implantada no Brasil com base nas experiências do Canadá.

Descritores: Óbito Fetal; Prática Profissional; Luto; Brasil; Canadá.

\section{RESUMEN}

Objetivo: comprender la atención profesional al duelo materno en el puerperio de los partos sin vida. Métodos: estudio clínico-cualitativo con todas las mujeres que tuvieron muerte fetal, residentes en Maringá (Brasil) y participantes en el Centre d'Études et de Recherche en Intervention Familiale de la Universidad de Quebec en Outaouais en Gatineau (Canadá). Se realizaron entrevistas semiestructuradas y se categorizaron los aspectos relevantes por temas. Resultados: las categorías identificadas fueron: Asistencia recibida en el puerperio con enfoque de duelo: ambiente hospitalario y ambulatorio y Apoyo profesional en el afrontamiento del duelo materno tras la pérdida fetal: con contacto y recuerdos, sin contacto y sin recuerdos e imposibilidades de contacto con el bebé. Consideraciones finales: la necesidad de una red de apoyo y monitoreo multiprofesional para mujeres que experimentaron pérdida fetal fue evidente. A partir de este estudio, se puede implementar una rutina de atención al duelo en Brasil a partir de las experiencias de Canadá.

Descriptores: Muerte Fetal; Práctica Profesional; Aflicción; Brasil; Canadá. 


\section{INTRODUCTION}

The World Health Organization (WHO) recommends routine puerperal assistance regarding the state of physical recovery due to the gestational and delivery process, from the first hour of birth to 24 hours afterwards, maintaining attention from the first day of delivery until discharge. Consultations should take place after delivery, an outpatient clinic between the $7^{\text {th }}$ and the $14^{\text {th }}$ day, another in six weeks, in addition to a home visit in the first week after delivery ${ }^{(1)}$.

The importance of postpartum care for the promotion and prevention of mother-child's health ${ }^{(2)}$ and in the identification of postpartum maternal depression ${ }^{(3-4)}$ is unquestionable. Still, not all women return for consultation, approximately $70 \%$ of mothers are assisted in Basic Health Units (BHU) with a Family Health Strategy and $47 \%$ of mothers are assisted in a traditional $\mathrm{BHU}^{(5)}$. This non-adherence to puerperal consultation is influenced by the inequity factor; women with lower income and education are the ones who do not have puerperal consultation in primary care ${ }^{(6)}$.

Since the postpartum care of mothers with live births is not performed in all cases ${ }^{(5)}$ and there are few studies presented in literature ${ }^{(2)}$, in relation to puerperal care with women who have had a fetal death, the number of studies is even smaller ${ }^{(7)}$. For puerperal women with lifeless births, in addition to physical assessments, the WHO recommends additional supports for women's mental health ${ }^{(1,7)}$, especially regarding complicated grief $^{(8-9)}$, the most possible situation to occur.

To monitor fetal mortality rates, only fetal death, also known as stillborn or stillbirth, is considered the death of a fetus occurring after the $22^{\text {nd }}$ complete week of gestation, or 154 days, or of fetuses weighing equal or greater than 500 grams, or height from 25 centimeters. Annually, more than 2.6 million pregnancies end in stillbirths worldwide, with variations of 25 per 1,000 births for underdeveloped countries, from 14.9 per 1000 births for countries in a gradual process of decreasing these deaths, such as Brazil, and the lowest rates with less than five per 1000 births for developed countries such as Canada and the United States ${ }^{(10)}$.

As a phenomenon, pregnancy is represented in psychological and social contexts as a result for birth, life, and hope. In this regard, fetal death means for mothers, fathers and family members a contradiction of the so-called natural order of the phases of life, referring to the paradox between life and death ${ }^{(7)}$. The impact of this loss can be devastating and last the rest of a mother's life, as there is a void, a state of hopelessness, which can evolve into psychological disorders ${ }^{(11)}$ such as depression, anxiety, post-traumatic stress disorder, and complicated grief ${ }^{(8-9)}$.

The pain and sadness of losing a baby before birth is unlike any other type of suffering, as it took months of planning and expectations for the misunderstanding of the birth of a dead child. This grieving process can be more complex and difficult, and be elaborated at the level of imagination, as there was no "visible" child to cry, there are no shared memories or life experiences. Death is usually sudden, and there is a lack of recognition of this loss by society ${ }^{(8,10)}$.

The grief of parents who experienced the loss of a baby, but did not have the opportunity to meet their baby, was different from other types of grief. The possibility of seeing and holding the baby is associated with less symptoms of post-traumatic stress ${ }^{(7)}$. Complicated grief, that state of persistent and incapacitating sadness in mothers who had a fetal death, is influenced by individuality, culture, and country in which they live ${ }^{(8-9)}$. Qualitative studies are essential to investigate the care needs of mothers who went through a fetal loss process ${ }^{(12)}$.

Based on the bibliography consulted, there is a need to recognize fetal death by society ${ }^{(13)}$, since parents' participation in the death process with the support of health professionals, family, and friends is essential to cope with and overcome the loss. Considering the literature, the study sought to answer the following questions: is the appropriate puerperal care in cases of fetal death the same between different countries? Is the role of health professionals in support to cope with grief for mothers who have had a fetal death different according to each country?

\section{OBJECTIVE}

To understand professional care for maternal grief in the puerperium of stillbirth.

\section{METHODS}

\section{Ethical aspects}

This study followed the norms of research involving human beings, according to Resolution 466/12 of the Brazilian National Health Council (Conselho Nacional de Saúde), and was approved by the Research Ethics Committee of Universidade Estadual de Maringa.

\section{Theoretical methodological framework}

The clinical-qualitative method has been used in the last decades in the health field, mainly in research involving themes of mental health, psychiatry, and obstetrics. This method gathers and refines generic qualitative methods in the field of human sciences, applying its scientific nature to human phenomena in the health field to describe and interpret the meanings of data to events and related to individuals' lives ${ }^{(14)}$.

In the clinical-qualitative method, the researcher is referred to as the central instrument of data collection through his listening and an accurate look from practice. Through it, the problems arising from clinical observation, supported by empiricism and theory linked to practice, are adequately sought. This method is an attitude of a professional health researcher in recognizing the meanings faced by patients in relation to the phenomena experienced in the health-disease process; and demonstration as experiences of subjects in their social group, a mold of individual life to cultural demarcation ${ }^{(14)}$.

\section{Type of study}

This is a qualitative exploratory study of a research partnership on maternal grief after fetal death in the reality of Brazil and Canada $^{(8-9)}$ through an agreement between the Graduate Course of Universities in these countries. While preparing this article, the criteria of the standard reports for qualitative research present in the $S R Q R^{(15)}$ were taken into account. 


\section{Methodological procedures}

\section{Study setting}

The census of Brazilian women $(n=30)$ who had a fetal death in 2013 in Maringa (PR), Brazil, registered in the Mortality Information System database until February 2014 and all Canadians ( $n=18$ ) who had a fetal death from 2010 to 2014, assisted at Center d'Études et de Recherche en Intervention Familiale (CERIF) at the University of Quebec in Outaouais, Gatineau (QC), Canada were selected.

The municipality of Maringa is located in northwestern Paraná $(P R)$, southern Brazil. The estimated population is 423.666 inhabitants in 2019, corresponding to the third most populous municipality in Paraná, with a Human Development Index (HDI) of 0.81 , sixth in this state ${ }^{(16)}$. The city of Gatineau belongs to the province of Quebec, in eastern Canada and is part of the metropolitan region of the country's capital, Ottawa, Ontario. It is the fourth city in importance in Quebec, with a population of 284.557 inhabitants in $2017^{(17)}$.

Inclusion criteria considered mothers whose address was located in Maringa after authorization by the municipal health department of deaths investigated by the mortality committee ( $\mathrm{n}$ $=26$ ), and mothers who participated in the grief support group at CERIF in Gatineau $(n=18)$. The exclusion criterion was not applied due to interviewees' receptive and persevering acceptance.

\section{Data collection and organization}

The strategy used for data collection was the clinical-qualitative method through a semi-structured interview, with Brazilian Portuguese being used for Brazilian participants and French for Canadians. The following open-ended questions were used: how was the postpartum priority in the hospital and at home? What contact did you have with the baby you lost?

The interviews were carried out by a health professional and researcher on the topic, with prior clarification on the research objectives and acceptance of participation by women in both countries within a period of up to one year after the death, according to the place reserved and chosen by interviewee. All Canadians and most Brazilians were interviewed at home, and three Brazilians made it available at work.

The disadvantages lasted about 80 minutes and were recorded on audio. Subsequently transcribed and subjected to readings and re-readings, seeking to identify relevant aspects that were categorized in discussions debated with the team of researchers belonging to the research, and a qualitative content analysis was carried out.

\section{Data analysis}

The semi-directed interview analysis was carried out after full transcription of all notes, and successive and exhaustive text skimming, seeking to identify relevant aspects. Subsequently, they were categorized into discussion games that correspond to the research objective. The discussion arguments were discussed in a team according to a qualitative content analysis, supported by the theoretical psychodynamic framework that involves the conceptual aspects of understanding the attitudes of mental states of people in movement, mainly as influences of unconscious levels ${ }^{(14)}$.

The amount of interviews was sufficient due to demonstration of data saturation or exhaustion, found in the repetition of similar or equal content expressed by several participants. Given the classifications of the postpartum period in scientific consensus, for the present study, the didactic division of immediate (from discharge to 2 hours), mediate (after 2 hours to 10 days), and late (after the $10^{\text {th }}$ day) puerperium was used ${ }^{(18)}$ for the specifications in hospital care (immediate puerperium) and outpatient care (mediate and late puerperium).

The results were organized into thematic categories and thematic nuclei, in order to systematize the ideas that contemplated the objective of the study, thus allowing inference to the results found and discussed based on literature. The first category identified was: Assistance received in the puerperium with a focus on grief and two thematic nuclei: hospital environment (immediate puerperium) and outpatient care in primary care and/or private practice (mediate and late puerperium). The second category was: Professional support in coping with maternal grief after fetal loss and three thematic nuclei: with contact and memories, without contact and without memories, and impossibilities of contact with the baby.

For the presentation of results, participants' anonymity was guaranteed, being identified with the initial letters of the countries Brazil (B)/Canada (C), and numbered according to the order of inclusion of participants. The names of hospitals and health services were also not disclosed.

\section{RESULTS}

The main causes of stillbirth in 22 weeks or more of gestation in Brazil and Canada were placenta, cord, and membrane complications, maternal conditions and congenital malformations. As for the characteristics of mothers and their gestation, maternal age between 20 to 34 years old predominated, $62 \%$ (B) and $81 \%$ (C); education level greater than or equal to 12 years, $27 \%(B)$ and $100 \%(C)$; employment relationship, $67 \%$ (B) and $83 \%$ (C); presence of a partner, $84 \%$ (B) and $100 \%(C)$; mean gestation duration of 30 weeks (B) and 26 weeks (C); previous losses, 19\% (B) and $44 \%$ (C); planned pregnancy, 35\% (B) and 100\% (C).

Even though some interviews occur in a longer time after the occurrence than in others, women have reported every detail of their loss. They described the sequence of events, with memories of the day of the week that occurred, weight and physiognomy of the fetus, people who were present, and how health professionals reported fetal death and conducted care. Thus, it was observed that when it comes to the death of a child, the feelings and suffering due to the circumstance of death are preserved and relived with each memory, and grief is not always forgotten over time.

In the context of the statements expressed, it was possible to perceive episodes common to women who experienced fetal loss according to each country. Consequently, with a clinicalqualitative approach to content analysis, two categories were identified with their thematic nuclei and according to the reality of each country. 


\section{Assistance received in the puerperium with a focus on grief: hospital and outpatient environment}

Professionals' performance in the hospital, considered assistance in the immediate puerperium, in Canada is seen and shown below as very satisfactory by women who experienced fetal loss.

After the loss, a pediatrician and gynecologist came several times to explain what had happened, because I had not understood everything the first time. (C9)

At the hospital, for medical interruption, nurses and gynecologists were "very, very, very good". I didn't expect to be treated with such respect and empathy. I felt that they understood that it was a painful ordeal for me and my husband. I would rather not have had to make the decision, and that it had happened spontaneously. (C10)

In Brazil, satisfaction in the hospital environment was not contemplated by all women. There was a need for women to receive information and assistance offered by hospital services and a multidisciplinary health team to assist and support decisionmaking in all aspects of this coping (physical, mental, and social).

I had a terrible view of the Hospital [...], but after I went there, I can't say anything, I was treated very well. (B1)

What is bad at the Hospital [...] during prenatal care is always the same, but when you need to be hospitalized, any physician [obstetrician] takes care of you on duty. (B13)

I was hospitalized several days after delivery, they said that a psychologist would visit me but she did not come. (B2)

However, the satisfaction of Canadians with good care is not always the same in the outpatient environment performed in all instances of primary care, in the so-called Center Local de Services Communautaires (CLSC), and their needs are met in professional support groups. There is no doubt about the need to receive professional assistance in the weeks and months that follow after death, as support for coping with grief.

After death, I had several contacts. I kept in touch with the hospital chaplain. I went to see a psychologist and participated in a support group for parents who had similar experiences. (C1)

The hospital nurse said that someone from CLSC would be contacting us ... it never happened. So, I called CLSC, and they said they didn't have anyone qualified, or that they felt comfortable with the grief to help us. So, I said "Ah, it's okay, because we are also not comfortable with the grief". (C9)

In the Brazilian reality, it was also evident the lack of strategies, skills and resources of health professionals in outpatient postpartum consultations. To meet the needs, women seek religious support to face this situation. Due to the lack of a professional support group in Brazil, there was no citation in the cases.

At first, we get angry, angry with the physician [cry]. Then I thought, for the man, it may be that he has some power, but by my faith, I believe that nothing happens if God does not allow it. So, I'm not going to give him this power of life and death, which he doesn't have. He could have been more efficient; he could have stopped earlier. But if it was in God's plan that the baby was going to die, he would die, even if he was born earlier. So, this was the way I managed not to be angry with the physician, because it is very bad. I couldn't even think or imagine seeing him in front of me. I didn't know what reaction I could have, if I could have a nervous breakdown, curse. (B5)

At the health clinic, they said they would make an appointment with the psychologist, but she went on vacation. (B2)

\section{Professional support in coping with maternal grief after fetal loss: with contact and memories, without contact and memories and impossibilities of contact with the baby}

Regarding contact with the dead baby, it is observed that Canadians are assisted by professionals with a focus on guidance on the grieving process; they receive various memories of the baby from the hospital staff, are encouraged to take pictures, and to see the baby even when they do not wish to do so, contrary to what happens with Brazilian women.

In Canada, therapeutic interruption of pregnancy for up to 23 weeks is possible in cases of malformations incompatible with life and when the woman makes this option. Therapeutic interruption, even in countries where it is legalized, is not accepted by the doctrines of Christianity. Thus, it is up to the religious members who participate in the health team to respect women's decisions on their autonomy as a human being.

I took all the souvenirs offered by the hospital staff: baptism, fingerprints, the identification bracelet and the service of a photographer. We spent about six hours with our daughter. I had time to pick her up, look at her, and see the extent of the abdominal mass, confirming that we had made the right decision. During the entire process of terminating the pregnancy, I felt heard by the professionals, except the chaplain. (C10)

For some women, fantasies created around the malformations are deconstructed when they see their babies. Seeing their babies materializes the imagination of visible malformations, and for nonvisible ones, perfection since it had made a worse image of them

The Brazilian women, with rare exceptions, were satisfied with hospital and primary care service. In the course of coping, faith was a support for women to go on with their lives. Religion is a demonstration of faith and women use it to make sense of and face the history experienced in that context, holding on to God for their greatest source of strength.

In Brazil, women have no contact with the dead baby, and when they do, it is quick and unassisted. Unpreparedness is observed, considering that health professionals do not encourage contact and when mothers wish to do so, they perceive this measure as harmful, an abnormality. In the Brazilian reality, women reported:

I didn't get to see the baby. It was bleeding a lot. My mother took a picture at the morgue, my husband took it at the funeral and I saw it later. (B14)

Before going to the room, the physician brought the baby for me to see, very tidy, and soon asked to take him because he couldn't 
stay long, he had to do tests. I didn't take a picture of him, my mother went to take it and someone from the hospital said that she couldn't do it inside. I picked him up just a little bit. (B8)

When I came back from anesthesia, the physician asked if I wanted to see it. She brought him wrapped up, he was perfect, beautiful. I couldn't get it, because my hands were tied. What I regret, is that I didn't get him, but God wanted it that way. (B11)

I took him, my mom took him too, and I even took a picture with him. They [professionals] even said with fun "look, they are trying to get the stillborn. She can't take him, she'll want to take him for her". I went to the funeral because they discharged me before. (B18)

Due to women's clinical conditions, contact with stillbirths was impossible. However, even after stabilization, it was not verified whether professionals allowed a new contact or even guided the family to take photos and or keep memories.

I didn't see the baby; I had just come out of surgery and the nurse called whoever wanted to see. My husband and a friend saw it. My husband did not take a picture and could not stand to stay long and my friend said she was perfect, resembling me and very big. (B21)

In some cases, a mother has no dimension of what is going on, and does not want to see her baby. Canadian health professionals seek to encourage this meeting with the dead baby.

The nurses insisted that I see the baby. Otherwise, the nurses would not let me down, since I did not want to speak. I did not want to take the memories, so as not to report memories of his birth at home. (C16)

Also, in Brazil, a woman did not have the desire to see the baby and justified it as her way of being. However, it expresses this decision as a later difficulty in realizing death and coping with grief. The mother who did not see the baby keeps the baby's "image" in her imagination, carrying this figure to other children, trying to idealize what her child would be like. Women's reports show the need for trained professionals to provide better care to women at this time.

The physician asked me to see it, but I didn't want to, my mother said she looked like me. But it's my way of being, my brother died 10 years ago and even today I don't see his photos and videos. I think that since I didn't want to see the baby, when I remember the baby, different faces of a child always see in my mind. (B1)

\section{DISCUSSION}

Unfortunately, the proposal for hospital care for professional performance in the face of a fetal death has not yet been implemented in several health services ${ }^{(19-20)}$. Interventions, assistance, and training for care provision in these situations represent an outstanding issue. The experience shows weakness in professionals' performance, who do not know how they should behave, nor how to monitor and care for women after suffering a fetal loss ${ }^{(6,8,21-22)}$.

In Brazil, health professionals feel little prepared to establish an empathic relationship and are unaware that an inappropriate attitude can influence the correct evolution of women's grief(20-22).
In order to improve the nursing care provided to women who have had a fetal death, an early assessment of the grieving process is essential, in order to schedule interventions necessary for each case $^{(8-9)}$. Different reactions were found with regard to providing memories of the baby, indicating that health professionals are unaware of the extent to which these options can help parents better overcome grief ${ }^{(22)}$.

Adequate puerperal care in cases of fetal death is not the same in different countries, mainly in support for the prevention of complicated grief. In Canada, hospital professionals explain what happened, dialogue and welcome women comprehensively and free of stigma and prejudice. Although outpatient care in primary care does not give the expected care in all cases, there are professional support groups for continuous care without a time limit for the time of loss. In Brazil, there are few cases with adequate puerperal care, regardless of the complexity of assistance. The limited care for maternal grief of lifeless births in Brazil reflects the impediment of actions carried out in Canada and provided for in literature of contact and memories of the fetus for support in coping with overcoming grief.

In some countries, through culture and tradition, women are encouraged not to interact with the dead baby after birth so that they discard the memories and do not talk about their loss. However, these cultural restrictions are predictors of grief ${ }^{(23)}$ and difficult for women, who demonstrate a desire for professional support and the need for social support ${ }^{(24)}$. In another cultural reality, the assistance protocol directs professionals not to force the mother to see her dead baby, although mothers' reports confirm their satisfaction in seeing them, even when they had not expressed their desire a priori ${ }^{(25)}$.

The grief of parents who experienced the loss of a baby, but did not have the opportunity to meet their baby, was different from other types of grief. The ability to see and hold the baby is associated with fewer symptoms of post-traumatic stress. Fears of seeing a damaged or dead body should be sensitively explored, and ways of coping, discussed. Even in cases where mothers experienced intense anguish during contact with their stillborn, they still describe that contact as being important and that they had made the right decision. This indicates the need to give parents an informed choice about the possible benefits and risks of seeing their baby born dead ${ }^{(25)}$.

Health professionals, in addition to offering support to their parents, also need training to guarantee and understand the support for this situation ${ }^{(7,23)}$. People who have experienced a similar problem before may be willing to provide more support than those who never had.

For the health team, the occurrence of fetal death is a frustration, a failure in this time of high technology, in which presumption prevails that deaths like these no longer occur, bringing to the fore also the unpreparedness for professional performance in some realities. An impotence is also felt when seeing patients' sadness and pain while assisting them in the hospital. Professionals are limited to help overcome this suffering, and whenever possible, request psychology assistance in cases $^{(21)}$.

Regarding the experiences of health professionals with groups of parents who had a fetal loss in Canada, successes are reported in their actions in contributing to the construction of a culture 
of support, affection, and respect for parents' grieving. Allowing bereaved parents to share their stories in public makes it possible to elucidate what can be done to prevent other families from experiencing the same suffering, and perhaps to help prevent the unnecessary death of another child.

Health professionals, in addition to offering support to their parents, also need training to guarantee support for this situation $^{(7,23)}$. Nurses who work in the delivery room manifest internal conflict about end of life in cases involving stillbirths. In addition to offering prayers and maintaining respect for the body of the stillborn baby, professionals revealed a feeling of discomfort and guilt, for not being able to provide an adequate farewell, and anxiety and empathy towards the mother when accompanying the farewell(26).

\section{Study limitations}

Among the limitations of this study, even with a small number of participants in the annual census of women with fetal death in a Brazilian municipality and Canadian women who participated in professional support by CERIF, a clinical-qualitative analysis ensured an understanding of the studied subject's perspective among the various acceptable interpretations. Group discussion of results among research researchers was considered to validate a correct result that is representative of the empirical reality and acceptable to the scientific community'.

\section{Contributions to nursing, health, and public policy}

The assistance practice when interviewing the Brazilian women provided a therapeutic moment of expression for women who do not have a professional support group, giving voice to the unattended reality, and built knowledge by participating in the support group in Canada. The internship abroad made it possible to learn about a care culture in a developed country and to be able to compare it with the reality of a developing country, for later implementation of this care model reference.

The results have implications for professional health practice by exposing fragile care to Brazilian mothers' grief, unpreparedness for care and even the absence of assistance for women, partners and other family members. The results show the importance of improving knowledge and qualifying nursing care and that of other health professionals in the area of grief for fetal death for adequate treatment and coping with this dramatic pregnancy complication. It is urgent to incorporate in Brazil public policies for maternal grief care.

\section{FINAL CONSIDERATIONS}

From interviewees' clinical status, the loss of a fetal death and the intention to guarantee an understanding of the perspective of the women studied according to each country, mainly involving the attitudes of their mental states and unconscious influences, qualitative analysis of content with discussion group of results among researchers presented a valid result, representative of the empirical reality and acceptable to the scientific community'.

Clinical cases reported how professional care for maternal grief happened and were felt by these women based on the sociocultural reality in the different circumstances and in the relationship with health services, religious institutions and people. Based on this study, a routine of grief care programs can be implemented in hospitals in Brazil according to Canadian experience.

As for contact with the dead baby, according to women's stories, regardless of gestational age, there is a whole ritual for Canadians to look at, take, care for and keep memories of their dead baby. Some Brazilians also had this opportunity, however, with limited time and sometimes in an embarrassing way in view of health professionals' attitudes, little prepared to deal with this situation.

Fetal loss implied reconstructing women's identity, in the reflection on the experienced moment, and brought wisdom to advise other women in grief support groups, with a view to avoiding processes similar to those experienced by them and recommendations to professionals and routines of health services, for better assistance in cases that still exist.

Given the implications of the theme of maternal grief after fetal death, the need for women who experienced fetal loss, like Canada, to be followed up by a multidisciplinary team and the importance of a support network became very evident. In Brazil, there is a need to expand the light technology of health dialogue, which, in addition to the existence of a professional support group service in these situations of loss, may benefit women in coping with grief.

\section{FUNDING}

This study was financed by Coordination for the Improvement of Higher Education Personnel (CAPES - Coordenação de Aperfeiçoamento de Pessoal de Nível Superior), under Process 99999.011586/2013-03.

\section{REFERENCES}

1. World Health Organization (WHO). Postnatal Care for Mothers and Newborns Highlights from the World Health Organization 2013 Guidelines [Internet]. Geneva (SWI): 2015 [cited 2020 Jan 15]. Available from: https://www.who.int/maternal_child_adolescent/publications/ WHO-MCA-PNC-2014-Briefer_A4.pdf

2. Andrade RD, Santos JS, Maia MAC, Mello DF. Factors related to women's health in puerperium and repercussions on child health. Esc Anna Nery. 2015;19(1):181-6. https://doi.org/10.5935/1414-8145.20150025

3. Aloise SR, Ferreira AA, Lima RFS. [Postpartum depression: identification of signs and symptoms and associated factors in reference maternity hospital in the city of Manaus]. Enferm Foco. 2019;10(3):41-5. https://doi.org/10.21675/2357-707X.2019.v10.n3.2455 Portuguese.

4. Spindola T, Penha LH, Lapa AT, Cavalcante ALS, Silva JMR, Santana RSC. The postpartum period from the perspective of women attended at a University Hospital. Enferm Foco. 2017;8(1):42-6. https://doi.org/10.21675/2357-707X.2017.v8.n1.847 
5. Oliveira RLA, Ferrari AP, Parada CMGL. Process and outcome of prenatal care according to the primary care models: a cohort study. Rev Latino-Am Enfermagem. 2019;27:e3058. https://doi.org/10.1590/1518-8345.2806.3058

6. Coutinho E, Amaral S, Parreira MVBC, Chaves CB, Amaral O, Nelas P. Nurses- puerperal mothers interaction: searching for cultural care. Rev Bras Enferm. 2019;72(4):910-17. https://doi.org/10.1590/0034-7167-2018-0216

7. Flenady V, Boyle F, Koopmans L, Wilson T, Stones W, Cacciatore J. Meeting the needs of parents after a stillbirth or neonatal death. BJOG. 2014;121(suppl4):137-40. https://doi.org/10.1111/1471-0528.13009

8. Paris GF, Montigny F, Pelloso SM. Factors associated with the grief after stillbirth: a comparative study between Brazilian and Canadian women. Rev Esc Enferm USP. 2016;50(4):546-53. https://doi.org/10.1590/S0080-623420160000500002

9. Paris GF, Montigny F, Pelloso SM. Cross-cultural adaptation and validation evidence of the perinatal grief scale. Texto Contexto Enferm, 2017;26(1):e5430015. https://doi.org/10.1590/0104-07072017005430015

10. Lawn JE, Blencowe H, Waiswa P, Amouzou A, Mathers C, Hogan D, et al. Stillbirths: rates, risk factors, and acceleration towards 2030 . Lancet. 2016;387:587-603. https://doi.org/10.1016/S0140-6736(15)00837-5

11. Bui E, Mauro C, Robinaugh DJ, Skritskaya NA, Wang Y, Gribbin C, et. al. The structured clinical interview for complicated grief: reliability, validity, and exploratory factor analysis. Depress Anxiety. 2015;9(32):485-92. https://doi.org/10.1002/da.22385

12. Mander R. Who listens to parents and is anything done? Practising Midwife[Internet]. 2014 [cited 2020 Jan 5];17(7):24-25. Available from: https://www.researchgate.net/publication/263702716_Who_listens_to_parents_and_is_anything_done

13. Kiguli J, Namusoko S, Kerber K, Peterson S, Waiswa P. Weeping in silence: community experiences of stillbirths in rural eastern Uganda. Glob Health Action. 2015;8(1):24011. https://doi.org/10.3402/gha.v8.24011

14. Turato EP. Tratado da metodologia da pesquisa clínico-qualitativa: construção teórico-epistemológica, discussão comparada e aplicação nas áreas da saúde e humanas. 4. ed. Rio de Janeiro: Vozes; 2010. 688 p.

15. Brien BCO, Harris IB, Beckman TJ, Reed DA, Cook DA. Standards for Reporting Qualitative Research. Acad Med. 2014;89(9):1245-51. https:// doi.org/10.1097/ACM.0000000000000388

16. Instituto Paranaense de Desenvolvimento Econômico e Social. Paraná em números [Internet]. Curitiba (BR): IPARDES; 2019 [cited 2019 Nov 8]. Available from: http://www.ipardes.gov.br/perfil_municipal/MontaPerfil.php?codlocal=309\&btOk=ok

17. Gatineau (Quebec). [Internet]. Florida (USA):Wikimedia Foundation; 2018 [cited 2019 Aug 10]. Available from: https://pt.wikipedia.org/wiki/ Gatineau_(Quebec)

18. Neme B. Obstetrícia básica. $3^{a}$ ed. São Paulo: Sarvier; 2005. 775 p.

19. Strefling IS, Lunardi Filho WD, Kerber NP, Soares MC, Ribeiro JP. Nursing perceptions about abortion management and care: a qualitative study. Texto Contexto Enferm. 2015;24(3):784-91. https://doi.org/10.1590/0104-07072015000940014

20. Rosner R. Prolonged grief: setting the research agenda. Eur J Psychotraumatol. 2015;19;19(6):2703. https://doi.org/10.3402/ejpt.v6.27303

21. Lemos LFS, Cunha ACB. Death in the maternity hospital: how health professionals deal with the loss. Psicol Estud. 2015;20(1):13-22. https:// doi.org/10.4025/psicolestud.v20i1.23885

22. Montero SMP, Sánchez JMR, Montoro CH, Crespo ML, Jaén AGV, Tirado MBR. Experiences with perinatal loss from the health professionals' perspective. Rev Latino-Am Enfermagem. 2011;19(6):1405-12. https://doi.org/10.1590/S0104-11692011000600018

23. Roberts LR, Lee JW. Autonomy and social norms in a three factor grief model predicting perinatal grief in India. Health Care Women Int. 2014;35(3):285-99. https://doi.org/10.1080/07399332.2013.801483

24. Tseng YF, Chen $\mathrm{CH}$, Wang $\mathrm{HH}$. Taiwanese women's process of recovery from stillbirth: a qualitative descriptive study. Res Nurs Health. 2014;37(3):219-28. https://doi.org/10.1002/nur.21594

25. Ryninks K, Roberts-Collins C, McKenzie-McHarg K, Horsch A. Mothers' experience of their contact with their stillborn infant: an interpretative phenomenological analysis. BMC Pregnancy Childbirth. 2014;13(14):203. https://doi.org/10.1186/1471-2393-14-203

26. Lin $\mathrm{CH}$, Cheng $\mathrm{KY}$, Chiang $\mathrm{HH}$. Saying goodbye to the newborn: the unease and actions of nursing professionals in handling stillbirth care. Hu Li Za Zhi. 2015;62(1):29-38. https://doi.org/10.6224/JN.62.1.29 